Vol 10, Issue 10, 2017

\title{
ENHANCEMENT OF THE DISSOLUTION RATE OF NATEGLINIDE TABLETS USING LIQUISOLID COMPACT TECHNIQUE
}

\author{
TIRUNAGARI MAMATHA*, NAZIA SULTANA
}

Department of Pharmaceutics, Sultan-ul-Uloom College of Pharmacy, Banjara Hills, Hyderabad, Telangana, India. Email: tmamatha12@gmail.com

Received: 13 May 2017, Revised and Accepted: 29 June 2017

\section{ABSTRACT}

Objective: The main objective of this work is to develop new formulation to enhance the solubility of a highly permeable and a poorly soluble oral drug antihyperglycemic agent, nateglinide by liquisolid compacts.

Methods: The liquisolid compact technique is based on dissolving the insoluble drug in propylene glycol, polyethylene glycol 400 , tween-80 as non-volatile solvents in which drug is having high solubility and admixture of drug loaded solution with microcrystalline cellulose as carrier, aerosil as coating material, crospovidone as disintegrant, and magnesium stearate as lubricant to convert into acceptably flowing and compressible powder. The prepared liquisolid compacts were evaluated for their flowing properties such as bulk density, tapped density, angle of repose, Hausner's ratio, and Carr's index. Further tablets were evaluated for hardness, thickness, weight variation, friability, disintegration test, and in vitro release study.

Result: Higher drug release profiles due to increased wetting property and surface area of the drug available for dissolution was obtained in case of liquisolid compacts. Among all formulations, liquisolid system prepared by propylene glycol was considered as best formulation which release drug up to $98 \%$ in 60 minutes and in comparison to marketed formulation, optimized formulation showed better dissolution profile.

Conclusion: It can be concluded that liquisolid compact technique could be a promising strategy in improving the dissolution of poor water soluble drugs.

Keywords: Antihyperglycemic agent, Liquisolid compact technique, Nateglinide, Propylene glycol.

(C) 2017 The Authors. Published by Innovare Academic Sciences Pvt Ltd. This is an open access article under the CC BY license (http://creativecommons. org/licenses/by/4. 0/) DOI: http://dx.doi.org/10.22159/ajpcr.2017.v10i10.19922

\section{INTRODUCTION}

One of the novel methods for promoting dissolution is the formation of liquisolid compacts. Liquisolid compact formulation mainly includes non-volatile solvent, disintegrant, drug candidate, carrier material, and coating material [1].

In this technique, liquid may be transformed into a free flowing, readily compressible, and apparently dry powder with the liquisolid technology by simple physical blending with selected excipients named as carrier and coating material. The liquid portion, which can be a liquid drug, a drug suspension or a drug solution in suitable non-volatile liquid vehicles, is incorporated into the porous carrier material [2]. Preferably, water-miscible organic solvent systems with high-boiling point such as propylene glycol, liquid polyethylene glycols (PEGs), or glycerine are best suitable as liquid vehicles. Once, the carrier is saturated with liquid, a liquid layer is formed on the particle surface which is instantly adsorbed by the fine coating particles. Thus, an apparently dry, free flowing, and compressible powder is obtained. Usually, microcrystalline cellulose (MCC) is used as carrier material and amorphous silicon dioxide (colloidal silica) as coating material. Fig. 1 represents the schematic representation of a liquisolid system [3].

Practically water-insoluble liquid and solid drugs can be formulated into liquisolid systems using the new formulation-mathematical model.

The present study was planned with the objective to prepare the liquisolid compacts of nateglinide (NTG) using various non-volatile solvents to improve dissolution rate of the drug.
NTG has been exploited as a new class of oral antidiabetic agent used in the management of Type 2 diabetes mellitus [4] (non-insulindependent diabetes mellitus) (Fig. 2). It belongs to the meglitinide class of short-acting insulin secretagogues. NTG is an amino acid derivative of D-phenylalanine which stimulates the secretion of insulin by binding to the adenosine triphosphate potassium channels in pancreatic beta cells. It induces an early insulin response to meals decreasing postprandial blood glucose levels [5]. It should only be taken with meals and meal-time doses should be skipped with any skipped meal. Its empirical formula is $\mathrm{C}_{19} \mathrm{H}_{27} \mathrm{NO}_{3}$ and molecular weight is 317.4226 .

Literature survey was performed on different liquisolid compacts such as repaglinide [6,7], famotidine [8], fenofibrate [9], glyburide [10], and efavereinz [11].

\section{MATERIALS AND METHODS}

Materials

NTG was gift sample from Glenmark pharmaceuticals. Propylene glycol and PEG 400 were obtained from India glycols limited, Hyderabad. Tween 80, aerosol, MCC, crospovidone, and magnesium stearate were procured from S.D. Fine Chemicals Ltd.

\section{Methods}

Pre-formulation studies

Drug-excipient compatibility studies $[12,13]$

In the preparation of tablet formulation, drug and excipients may interact as they are in close contact with each other, which could lead to the instability of drug. Fourier-transform infrared (FT-IR) spectroscopy (FT-IR spectroscopy, Shimadzu, Japan) was employed to ascertain the 
compatibility between drug and the selected excipients. The pure drug and drug with excipient were scanned separately.

\section{FT-IR spectroscopy}

The functional group analysis for the excipients is done using the FT-IR method analysis. Initially, the samples were made into pellets using a pelletizer under a pressure of $100 \mathrm{~kg} / \mathrm{cm}^{2}$. A blank potassium bromide $(\mathrm{KBr})$ pellet is made, and then, a few mg of sample is mixed with $\mathrm{KBr}$ and made into pellet. All the pellets are analyzed by FT-IR instrument, and the data are processed using FT-IR system in the wave number range of $4000-400 \mathrm{~cm}^{-1}$.

\section{Analytical method development}

Preparation of phosphate buffer $\mathrm{pH} 6.8$ solution

$50 \mathrm{ml}$ of the $0.2 \mathrm{M}$ monobasic potassium phosphate solution was taken in a $200 \mathrm{ml}$ volumetric flask and $22.4 \mathrm{ml}$ of $0.2 \mathrm{M}$ sodium hydroxide solution was added to it, and then, water was used to make up the volume.

\section{Determination of $\lambda_{\max }$ of NTG in phosphate buffer $\mathrm{pH} 6.8$ solution}

Working standard

$100 \mathrm{mg}$ of NTG was weighed and dissolved in $5 \mathrm{ml}$ methanol, and then, the volume was made up to $100 \mathrm{ml}$ with phosphate buffer $\mathrm{pH} 6.8$ solution to give $1000 \mu \mathrm{g} / \mathrm{ml}$ concentrated stock solution.

Dilution 1: From the working standard solution $10 \mathrm{ml}$ was diluted to $100 \mathrm{ml}$ with phosphate buffer $\mathrm{pH} 6.8$ solution to give $100 \mu \mathrm{g} / \mathrm{ml}$ concentrated solutions.

Dilution 2: From dilution-1, $10 \mathrm{ml}$ solution was diluted to $100 \mathrm{ml}$ with phosphate buffer pH 6.8 solutions to give $10 \mu \mathrm{g} / \mathrm{ml}$ concentrated solutions.

This solution was scanned at a range of 200-400 $\mathrm{nm}$ wavelengths. The corresponding scan spectrum curve was noted and the wavelength having highest absorbance is noted as $\lambda_{\max } 217 \mathrm{~nm}$.
Construction of calibration curve of NTG in phosphate buffer $\mathrm{pH} 6.8$ solution

From dilution-1, 0.2, 0.4, 0.6, 0.8, and $1 \mathrm{ml}$ of solutions were taken and were made up to the mark in $10 \mathrm{ml}$ volumetric flask to obtain 2 , $4,6,8$, and $10 \mu \mathrm{g} / \mathrm{ml}$ concentrated solutions. The absorbance of these solutions was noted at $\lambda_{\max } 217 \mathrm{~nm}$.

Formulations of NTG liquisolid compacts are shown in Table 1

\section{Pre-compression studies [14]}

Bulk density

An accurately weighed sample of powder was carefully added to the measuring cylinder with the aid of funnel. The level was observed without compacting and noted as apparent volume $\left(\mathrm{V}_{0}\right)$. The bulk density $\left(D_{b}\right)$ was calculated by the formula as given below:

$D_{b=} \frac{M}{V_{0}}$

Where, $\mathrm{M}=$ Mass of powder taken, $\mathrm{V}_{0}=$ Apparent untapped volume.

Tapped density

It is the ratio of total mass of powder to the tapped volume of powder. The volume was measured by tapping the powder for 500 times. Then, the tapping was done for 750 times and the tapped volume was noted (the difference between these two volumes should be $<2 \%$ ). If it is more than $2 \%$, tapping is continued for 1250 times and tapped volume was noted. It is expressed in $\mathrm{g} / \mathrm{cc}$ and is given by formula:

Tapped density=Weight of powder/tapped volume

Carr's index

The percentage compressibility of powder is direct measure of the potential of powder arch or bridge strength. It is calculated according to the equation given below:

Compressibility index $=($ Tapped density - bulk density $) \times 100 /$ tapped density

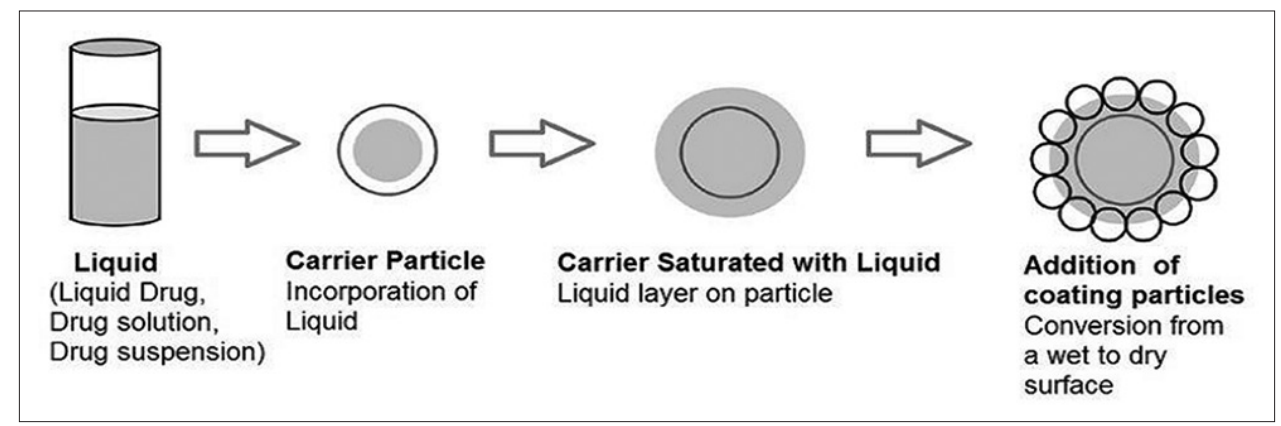

Fig. 1: Schematic representation of liquisolid system

Table 1: Composition of nateglinide liquisolid compacts

\begin{tabular}{|c|c|c|c|c|c|c|c|c|c|}
\hline \multirow[t]{2}{*}{ Ingredients } & \multicolumn{9}{|c|}{ Formulations (mg/tab) } \\
\hline & F1 & F2 & F3 & F4 & F5 & F6 & F7 & F8 & F9 \\
\hline Nateglinide & 60 & 60 & 60 & 60 & 60 & 60 & 60 & 60 & 60 \\
\hline Propylene glycol & 40 & 60 & 80 & - & - & - & - & - & - \\
\hline Tween 80 & - & - & - & 40 & 60 & 80 & - & - & - \\
\hline PEG 400 & - & - & - & - & - & - & 40 & 60 & 80 \\
\hline MCC & 225 & 205 & 185 & 225 & 205 & 185 & 225 & 205 & 185 \\
\hline Aerosil & 10 & 10 & 10 & 10 & 10 & 10 & 10 & 10 & 10 \\
\hline MCC & 50 & 50 & 50 & 50 & 50 & 50 & 50 & 50 & 50 \\
\hline Crospovidone & 10 & 10 & 10 & 10 & 10 & 10 & 10 & 10 & 10 \\
\hline Magnesium stearate & 2 & 2 & 2 & 2 & 2 & 2 & 2 & 2 & 2 \\
\hline Tablet weight (mg) & 397 & 397 & 397 & 397 & 397 & 397 & 397 & 397 & 397 \\
\hline
\end{tabular}

NTG: Nateglinide, PEG: Polyethylene glycol, MCC: Microcrystalline cellulose 


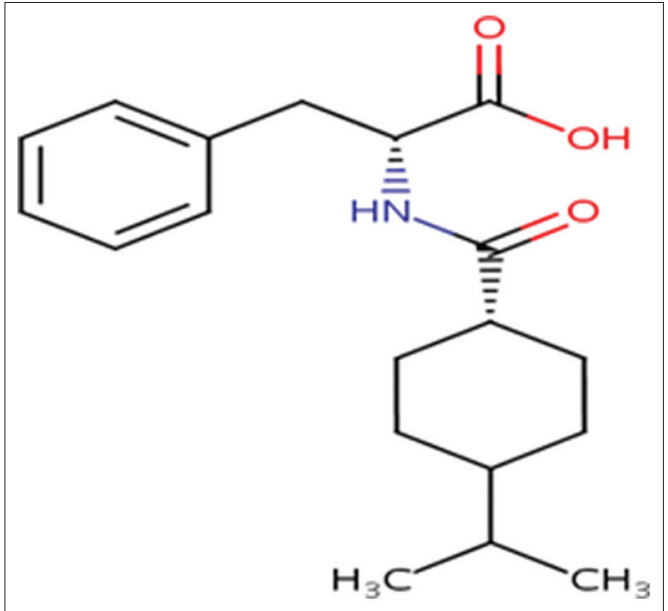

Fig. 2: Structure of nateglinide

Hausner's ratio

It is the ratio of tapped density to bulk density. It is related to inter particle friction and could be used to predict powder flow properties. The Hausner's ratio is calculated by the formula as given below:

Hausner's ratio $=\frac{\text { Tapped density }}{\text { Bulk density }}$

Angle of repose

It is defined as the maximum angle possible between the surface of a pile of powder and the horizontal plane. Angle of repose was calculated using the following formula.

$\theta=\tan ^{-1}(\mathrm{~h} / \mathrm{r})$

Where, $\theta=$ Angle of repose, $\mathrm{h}=$ Height $(\mathrm{cm})$, $\mathrm{r}=$ Radius $(\mathrm{cm})$.

The angle of repose has been used to characterize the flow properties of solids. It is a characteristic related to inter particulate friction or resistance to movement between particles.

\section{Direct compression method}

Direct compression method was used for the formulation of NTG tablets. Main advantages of direct compression are low manufacturing cost and high mechanical integrity of the tablet [15].

1. NTG drug was initially dispersed in the non-volatile solvent systems (tween-80, PEG 400) termed as liquid vehicles with the different drug: Vehicle ratio.

2. Carrier, MCC was added to the above liquid preparation by continuous mixing for 10-20 minutes in a mortar to evenly distribute liquid medication into powder.

3. To the above mixture aerosil, as coating material and remaining quantity of MCC was added and mixed thoroughly.

4. Mixture of crospovidone, disintegrant, and other remaining additives such as lubricant, magnesium stearate are added, and mixed in a mortar.

5. The final mixture was punched into tablet using $10 \mathrm{~mm}$ diameter punch.

\section{Evaluation of formulated tablets}

Weight variation [16]

Twenty tablets were selected and weighed collectively and individually. From the collective weight, average weight was calculated. Each tablet weight was then compared with average weight to assure whether it was within permissible limits or not.

$\%$ weight variation $=\frac{\text { Average weight }- \text { weight of each tablet }}{\text { Average weight }} \times 100$
Thickness

Thickness of the tablets was determined using vernier calipers.

Hardness test

Hardness of the tablet was determined using the Monsanto hardness tester. The lower plunger was placed in contact with the tablet and a zero reading was taken. The plunger was then forced against a spring by turning a threaded bolt until the tablet fractured. As the spring was compressed a pointer rides along a gauge in the barrel to indicate the force.

Friability [17]

Friability of the tablets was checked using Roche Friabilator. The device subjects a number of tablets to the combined effect of abrasions and shock by utilizing a plastic chamber that revolves at $25 \mathrm{rpm}$ dropping the tablets from a height of 6 inches with each revolution. Pre-weighed sample tablets were placed in the friabilator, which was then operated for 100 revolutions. Tablets were dusted and reweighed. The difference in the weight is noted and expressed as percentage.

It should be preferably between $0.5 \%$ and $1.0 \%$.

Friability $=\left[\left(\mathrm{W}_{1}-\mathrm{W}_{2}\right) / \mathrm{W}_{1}\right] \times 100$

Where, $\mathrm{W}_{1}=$ Weight of tablets before test, $\mathrm{W}_{2}=$ Weight of tablets after test.

\section{Content uniformity test [18]}

Ten tablets were weighed and powdered, a quantity of powder equivalent to $10 \mathrm{mg}$ of NTG was transferred to a $100 \mathrm{ml}$ volumetric flask and $10 \mathrm{ml}$ methanol is added. The drug is extracted in methanol by vigorously shaking the stoppered flask for 15 minutes. Then, the volume is adjusted to the mark with phosphate buffer $\mathrm{pH} 6.8$ and the liquid is filtered. From prepared solution take $0.1 \mathrm{ml}$ solution in $10 \mathrm{ml}$ volumetric flask and makeup to mark with phosphate buffer $\mathrm{pH} 6.8$. The NTG content was determined by measuring the absorbance at 217 $\mathrm{nm}$ after appropriate dilution. The drug content was calculated using the standard calibration curve. The mean percent drug content was calculated as an average of three determinations.

In vitro disintegration study [19-21]

The in vitro disintegration test for prepared tablets was carried out using USP disintegration test apparatus. Six tablets were placed individually in each tube of disintegration test apparatus, and discs were placed over each tablet. Distilled water was used as the medium which is maintained at $37 \pm 2^{\circ} \mathrm{C}$ and the time taken for each tablet to disintegrate completely was recorded.

\section{In vitro dissolution rate [22]}

In vitro dissolution of NTG tablets was studied in USP XXIII Type 2 dissolution apparatus employing a paddle stirrer at $50 \mathrm{rpm} .900$ $\mathrm{ml}$ of phosphate buffer $\mathrm{pH} 6.8$ was used as dissolution medium. The temperature of dissolution medium was maintained at $37 \pm 0.5^{\circ} \mathrm{C}$ throughout the experiment. Samples of dissolution medium $(5 \mathrm{ml})$ were withdrawn by means of syringe fitted with pre-filter at known intervals of time $(5,10,15,20,30,40,45$, and 60 minutes $)$ and analyzed for drug release by measuring the absorbance at $217 \mathrm{~nm}$. The volume withdrawn at each time interval was replaced with fresh quantity of dissolution medium. Cumulative percent NTG released was calculated and plotted against time.

\section{RESULTS}

\section{Pre-formulation studies}

Construction of standard calibration curve of NTG in phosphate buffer $\mathrm{pH} 6.8$

The absorbance of the solution was measured at $217 \mathrm{~nm}$, using UV spectrophotometer with phosphate buffer $\mathrm{pH} 6.8$ as blank. A graph 
of absorbance versus concentration was plotted which indicated in compliance to Beer's law in the concentration range $2-10 \mu \mathrm{g} / \mathrm{ml}$.

Standard plot of NTG was plotted by taking absorbance on Y-axis and concentration $(\mu \mathrm{g} / \mathrm{ml})$ on X-axis; the plot is shown in Fig. 3.

The standard calibration curve of NTG pH 6.8 phosphate buffers showed good correlation with regression value of 0.999 .

Drug excipient compatibility studies (FT-IR spectroscopy) (Figs. 4 and 5)

The FTIR spectrum of pure NTG showed an absorption band at $2924 \mathrm{~cm}^{-1}$ (aliphatic -H stretching, asymmetric), $2859 \mathrm{~cm}^{-1}$ (aliphatic $\mathrm{CH}$ stretching, symmetric), $1636 \mathrm{~cm}^{-1}(\mathrm{C}=0$ stretching for ketone), and $3086 \mathrm{~cm}^{-1}$ (aromatic $\mathrm{C}=\mathrm{H}$ stretching).

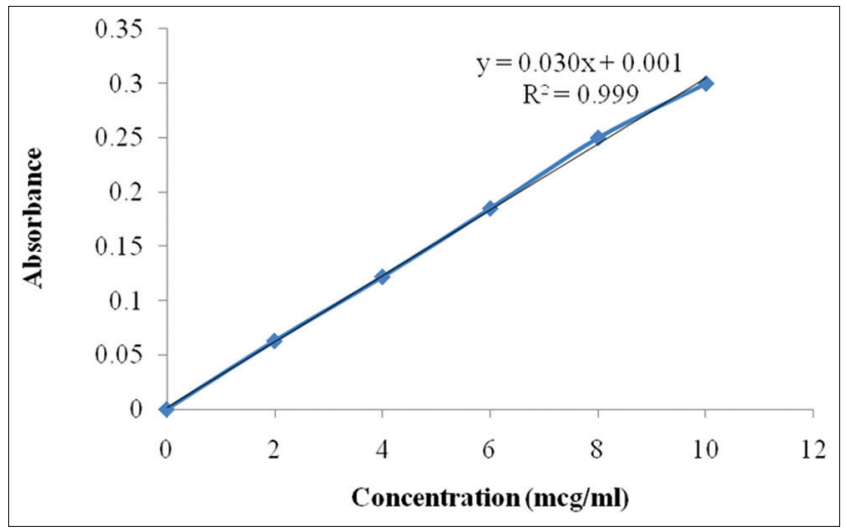

Fig. 3: Calibration curve for nateglinide in 6.8 phosphate buffer
Drug and excipients absorption bands were identified and interpreted in the spectra. The FT-IR spectra of physical mixtures of drug and excipients reveal no interaction between drug and excipients. The FTIR studies from the spectra confirmed the absence of any chemical interaction between the drug and the excipients.

\section{Pre-compression studies}

The prepared powders were evaluated for their flow properties; the results for the blends of compression tablets were shown in Table 2 .

The bulk density for all formulations was found to be in range $0.82-0.96 \mathrm{~kg} / \mathrm{cm}^{3}$ and the tapped density for all formulations was found to be in range $0.88-1.11 \mathrm{~kg} / \mathrm{cm}^{3}$.

The Carr's index and Hausner's ratio were found to be in the range of $<16$ and 1.07-1.18, respectively, indicating good flow and compressibility of the blends.

The angle of repose for all the formulations was found to be 25.3-35.6 which indicates passable flow (i.e., incorporation of glidant will enhance its flow). Hence, prepared powders were compressed into tablets and evaluated.

\section{Post-compression studies (Table 3)}

The variation in weight was within the limits complying with pharmacopoeia specifications of USP. The hardness for different formulations was found to be between 2.9 and $3.2 \mathrm{~kg} / \mathrm{cm}^{2}$, indicating satisfactory mechanical strength. The friability was $<1.0 \%$ for all the formulations, which is an indication of good mechanical resistance of the tablet.

The drug content was found to be within limits 98.2-101.2\%. Disintegration time for all the formulations was found to be 21-34 seconds.

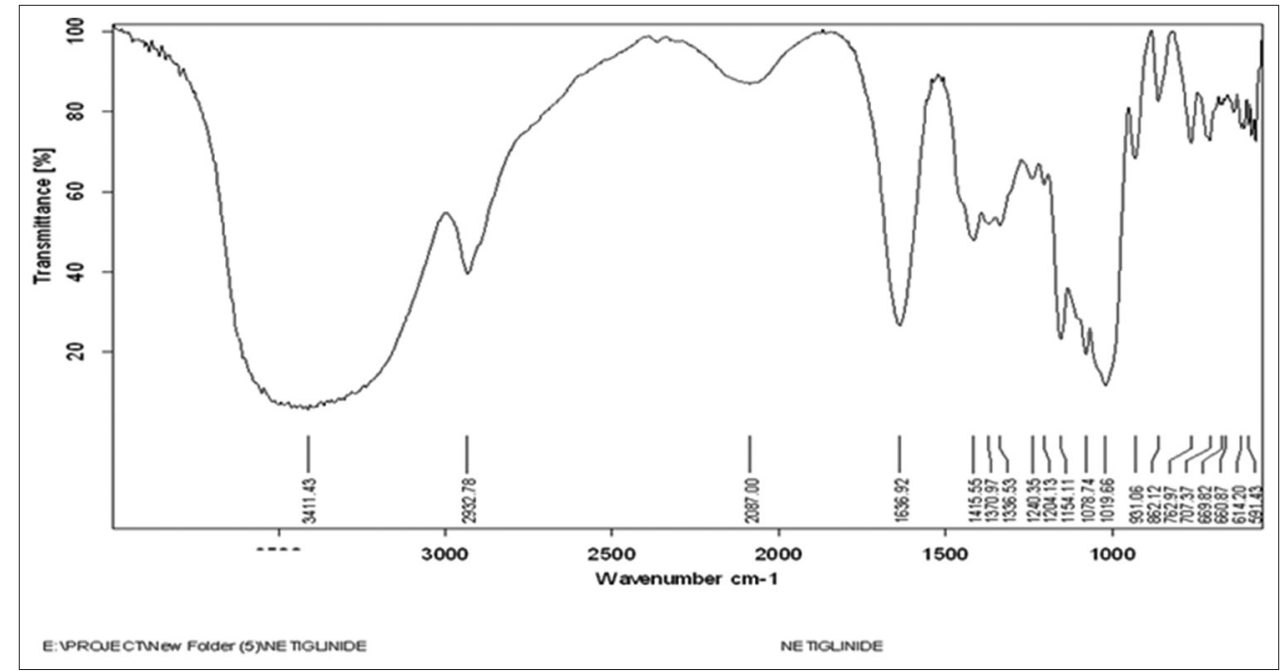

Fig. 4: Fourier-transform infrared spectra of nateglinide

Table 2: Pre-compression studies of nateglinide liquisolid formulations

\begin{tabular}{|c|c|c|c|c|c|}
\hline Formulation code & Bulk density (g/cc) & Tapped density (g/cc) & Carr's index & Hausner's ratio & Angle of repose $\left({ }^{\circ}\right)$ \\
\hline $\mathrm{F} 1$ & $0.96 \pm 0.52$ & $1.06 \pm 0.14$ & $9.6 \pm 3.8$ & $1.11 \pm 0.3$ & $27.3 \pm 2.9$ \\
\hline $\mathrm{F} 2$ & $0.86 \pm 0.23$ & $0.98 \pm 0.13$ & $12.1 \pm 0.4$ & $1.14 \pm 0.8$ & $31.2 \pm 1.2$ \\
\hline F3 & $0.85 \pm 0.36$ & $0.98 \pm 0.24$ & $13.6 \pm 0.9$ & $1.16 \pm 0.17$ & $35.6 \pm 1.4$ \\
\hline $\mathrm{F} 4$ & $0.94 \pm 0.44$ & $1.11 \pm 0.33$ & $15.1 \pm 0.8$ & $1.18 \pm 0.28$ & $29.6 \pm 2.6$ \\
\hline F5 & $0.89 \pm 0.52$ & $1.04 \pm 0.52$ & $14.3 \pm 0.6$ & $1.17 \pm 0.6$ & $25.3 \pm 2.8$ \\
\hline F6 & $0.82 \pm 0.66$ & $0.88 \pm 0.29$ & $6.6 \pm 1.4$ & $1.07 \pm 0.1$ & $29.2 \pm 1.9$ \\
\hline F7 & $0.85 \pm 0.39$ & $0.96 \pm 0.28$ & $11.9 \pm 0.5$ & $1.13 \pm 0.5$ & $31.6 \pm 1.7$ \\
\hline F9 & $0.89 \pm 0.48$ & $1.04 \pm 0.85$ & $14.3 \pm 0.8$ & $1.17 \pm 0.2$ & $25.3 \pm 1.3$ \\
\hline
\end{tabular}


Table 3: Post-compression studies of nateglinide liquisolid compacts

\begin{tabular}{|c|c|c|c|c|c|c|}
\hline Formulation & $\begin{array}{l}\text { Weight } \\
\text { variation }\end{array}$ & Hardness $\left(\mathrm{kg} / \mathrm{cm}^{2}\right) \pm \mathrm{SD}$ & Thickness $(\mathrm{mm}) \pm \mathrm{SD}$ & Friability (\%) \pm SD & Drug content $(\%) \pm S D$ & $\begin{array}{l}\text { Disintegration } \\
\text { time }(s) \pm S D\end{array}$ \\
\hline $\mathrm{F} 1$ & Pass & $2.9 \pm 0.8$ & $4.3 \pm 0.18$ & $0.82 \pm 0.07$ & $99.1 \pm 0.21$ & $34 \pm 0.028$ \\
\hline F2 & Pass & $3.2 \pm 0.16$ & $4.7 \pm 0.2$ & $0.48 \pm 0.04$ & $98.5 \pm 0.13$ & $25 \pm 0.042$ \\
\hline F3 & Pass & $3.1 \pm 0.9$ & $4.4 \pm 0.7$ & $0.67 \pm 0.08$ & $99.1 \pm 0.45$ & $21 \pm 0.031$ \\
\hline F4 & Pass & $2.9 \pm 0.4$ & $4.6 \pm 0.5$ & $0.33 \pm 0.04$ & $101.2 \pm 0.37$ & $28 \pm 0.014$ \\
\hline F5 & Pass & $3.0 \pm 0.24$ & $4.3 \pm 0.7$ & $0.95 \pm 0.03$ & $99.5 \pm 0.67$ & $24 \pm 0.018$ \\
\hline F6 & Pass & $3.2 \pm 0.31$ & $4.6 \pm 0.6$ & $0.34 \pm 0.02$ & $100.2 \pm 0.12$ & $30 \pm 0.035$ \\
\hline F8 & Pass & $3.0 \pm 0.32$ & $4.7 \pm 0.9$ & $0.65 \pm 0.06$ & $98.2 \pm 0.67$ & $28 \pm 0.062$ \\
\hline F9 & Pass & $3.1 \pm 0.22$ & $4.4 \pm 0.3$ & $0.42 \pm 0.08$ & $99.3 \pm 0.45$ & $31 \pm 0.035$ \\
\hline
\end{tabular}

SD: Standard deviation

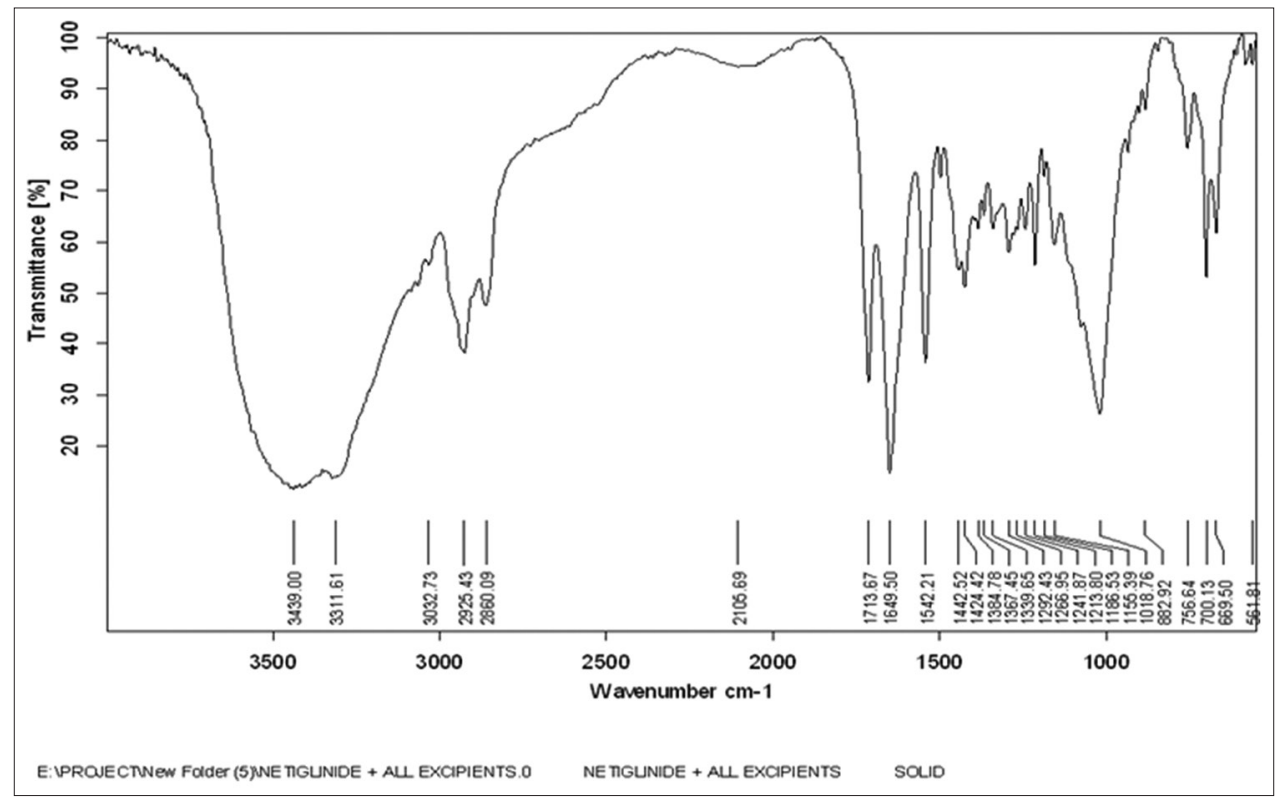

Fig. 5: Fourier-transform infrared spectra of nateglinide and excipients

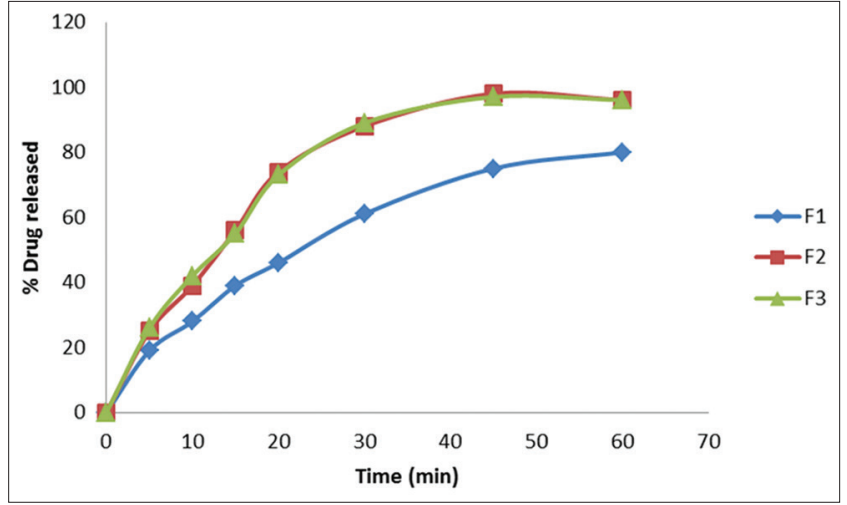

Fig. 6: Comparative dissolution profiles of F1, F2, and F3 formulations

In vitro dissolution studies of NTG liquisolid compact

Dissolution tests were performed for formulations F1-F9. From in vitro release study, it has been observed that the formulations F2, F3 showed higher drug release indicating that increase in non-volatile solvent concentration increase the dissolution of drug (Fig. 6)

From in vitro release study for tween 80 used formulations, it has been observed that the formulation F6 showed higher drug release indicating that increase in non-volatile solvent concentration increases the dissolution of drug (Fig. 7).
From in vitro release study of PEG 400 used formulations, it has been observed that the formulations F9 showed higher drug release indicating that increase in non-volatile solvent concentration increase the dissolution of drug (Fig. 8).

The results indicated that the increase in concentration of solubility enhancing agent will increase the dissolution of drug. Among all the formulations, F2 was selected as an optimized formulation because it shows higher drug release at less concentration of propylene glycol than other formulations. Based on mathematical data, it was concluded that the release data were best fitted with first order kinetic and follows Higuchi model.

The optimized formulation dissolution profile was compared with market formulation dissolution profile (Fig. 9).

From dissolution data, it was observed that more than $90 \%$ of the drug were released from both liquisolid and marketed formulation in 60 minutes in phosphate buffer $\mathrm{pH} 6.8$.

\section{DISCUSSION}

Liquisolid compact technology is one of the advanced methods of formulation for poor dissolving drugs. This type of formulation includes drug candidate, non-volatile solvent, disintegrant, carrier, and coating material. Liquisolid compact technology produces dry, free flowing, and compressible powders. Like glibenclamide, NTG also belongs to Biopharmaceutical Classification System Class II [23]. 


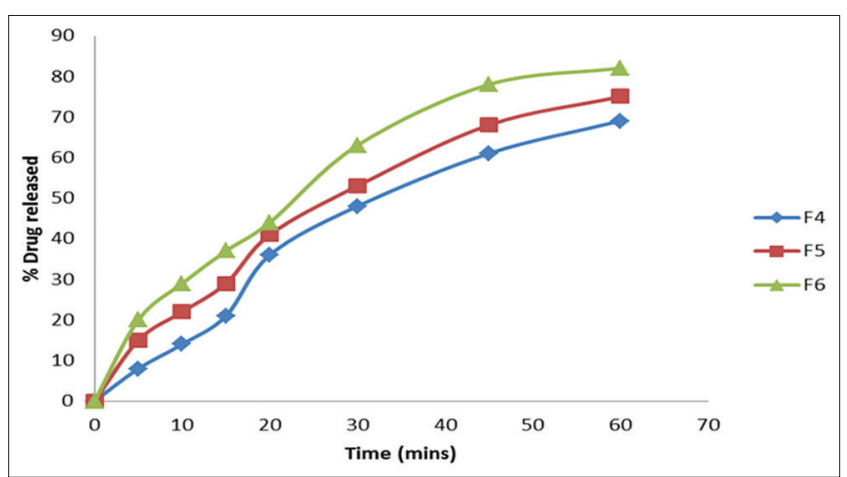

Fig. 7: Comparative dissolution profiles of F4, F5, and F6 formulations

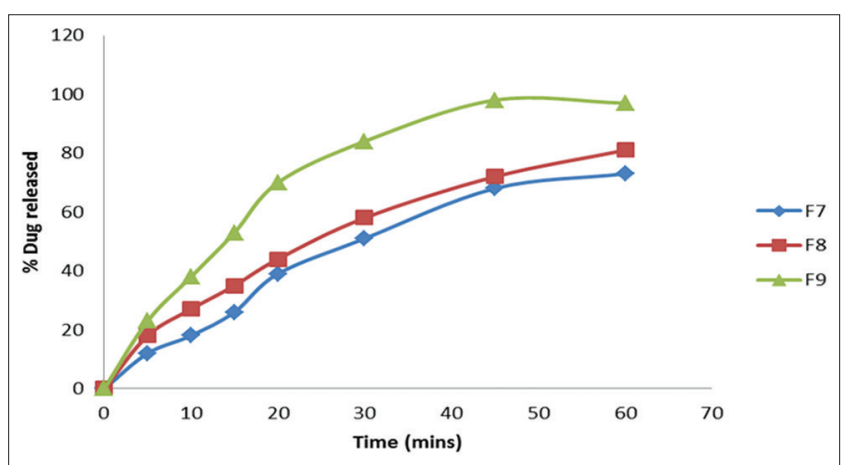

Fig. 8: Comparative dissolution profiles of F7, F8, and F9 formulations

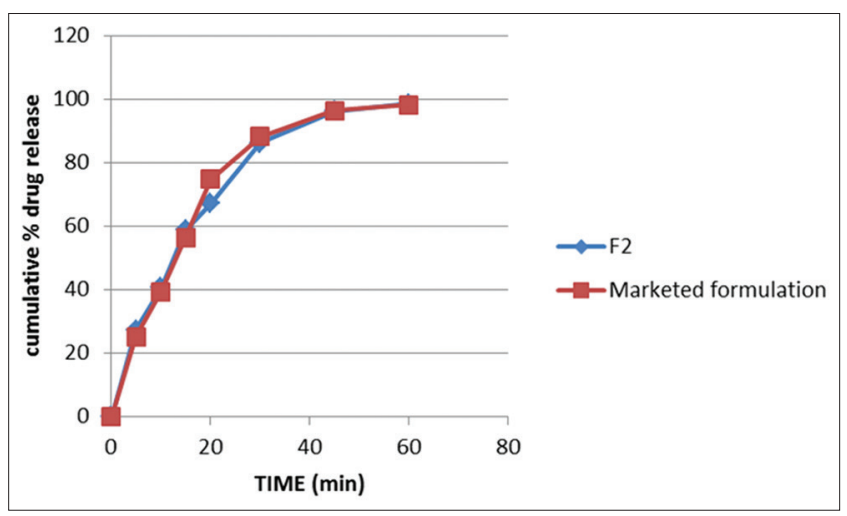

Fig. 9: Comparative dissolution profiles of marketed and optimized formulation

Solubility studies were conducted like that of Sirisha et al. for enhancement of dissolution of glibenclamide [23]. We have selected propylene glycol, tween 80 , and PEG 400 as non-volatile solvents.

NTG was formulated in triplicate. F1-F3 used Propylene glycol, F4-F6 used tween 80 whereas F7-F9 used PEG 400 as non-volatile solvents. It used MCC as carrier, aerosil as coating material, crospovidone as disintegrant and magnesium stearate as lubricant. Propylene glycol was used as surfactant/cosurfactant by Maghraby et al. to increase the dissolution of repaglinide drug [7].

In the pre-formulation study, initially, NTG drug solution was checked for obeying Beer's law. It was observed that drug solution in the range of $2-10 \mu \mathrm{g} / \mathrm{ml}$ obeyed Beer's law at wavelength of $217 \mathrm{~nm}$. To check drug-excipient compatibility, which is a major step in the process of formulating tablets FT-IR study was carried out. It was done in the wave number range of 4000-400 $\mathrm{cm}^{-1}$. From the FT-IR absorption bands, it was interpreted and confirmed that there is no interaction between drug NTG and other excipients.

Pre-compression studies for all the nine formulations, i.e., F1 to F9 were carried out. The results of Bulk density, Carr's index, Hausner's ratio, and angle of repose for all the formulations were found to be within pharmacoepoeial specified limits. Hence, the prepared powders could be compressed and were further evaluated for post compression studies.

Post-compression studies included evaluation for weight variation, hardness, thickness, friability, and drug content along with assessment of disintegration time. All the above said post-compression parameters were found to be within specified pharmacopoeial limits. Finally, tablets developed with minimum weight variation, sufficient mechanical strength, and less disintegration time.

Pre- and post-compression study was done similar to that of Rosuvastatin by Neelamma et al. [24] and glibenclamide by Sirisha et al. [23].

For all the 9 formulations in vitro dissolution study was carried out. Among the first three formulations which had used as non-volatile solvent $\mathrm{F} 2$ and $\mathrm{F} 3$ showed better results. In the next three formulations (F4-F6) using tween 80 as solvent, F6 was preferred. In the last three formulations (F7-F9) using PEG 400 as solvent, F9 was selected. From the above-selected formulations, it can be inferred that higher drug release can be achieved with increase in non-volatile solvent concentration.

From the above-preferred formulations, F2 was optimised for further study. Its dissolution profile was compared with that of the marketed formulation. From the dissolution profiles of optimized and marketed formulation it was concluded that optimized formulation was equally or better releasing the drug as to that of marketed formulation.

The reason for better dissolution rate of optimized formulation can be attributed to the drug presenting in a solubilized state in the formulation (liquisolid formulation), which contributes to increased wetting properties, thereby enhancing the dissolution rate. The results also hinted that with the increase in solubility enhancing agent, dissolution of the drug increases.

\section{CONCLUSION}

The research work done for the novel formulation of high permeable and low solubility antihyperglycemic drug NTG by liquisolid compact technology was successful. As the drug will be presented in a state of molecular dispersion, the formulation disintegrates in dissolution media. This will increase the effective surface area of the particles available for dissolution. Parison to marketed formulation our optimized formulation showed better dissolution profile. Hence, the liquisolid compact is the promising tool for enhancement of solubility of water insoluble drug.

\section{ACKNOWLEDGMENT}

The authors are thankful to Glenmark pharmaceuticals for providing the pure drug, NTG as gift sample and to the management of Sultan-ulUloom College of Pharmacy for providing necessary facilities to carry out the research work.

\section{REFERENCES}

1. Walke PS, Pawar AY, Sonawane DD, Bhamber RS. Liquisolid: A novel technique to enhance solubility and dissolution rate of BSC Class II pharmaceutical. J Pharm Res 2011;4(11):4011-4.

2. Thakur N, Khokra SL, Sharma D, Thakur NS, Purohit R, Arya V. A review on pharmaceutical applications of liquisolid technique. Am J PharmTech Res 2011;1(3):1-18.

3. Baby DA, Saroj S, Sabitha M. Mechanism of solubility of liquisolid 
formulation in non-volatile solvent: A review. Int J Pharm Pharm Sci 2012;4(3):710-5

4. Gopi G, Kannan K. Formulation development and optimization of nateglinide-loaded ethyl cellulose nanoparticles by box-behnken design. Int J Pharm Pharm Sci 2015;7(9):310-5.

5. Halas CJ. Nateglinide. Am J Health Syst Pharm 2001;58(13):1200-5.

6. El-Houssieny BM, Wahman L, Arafa NM. Bioavailability and biological activity of liquisolid compact formula of repaglinide and its effect on glucose tolerance in rabbits. Biosci Trends 2010;4(1):17-24

7. El-Maghraby GM, Osman MA, Abd-Elrahman HE, Elsisi AE. Selfemulsifying liquisolid tablets for enhanced oral bioavailability of repaglinide: In vitro and in vivo evaluation. J Appl Pharm Sci 2014;4(9):12-21.

8. Fahmy RH, Kassem MA. Enhancement of famotidine dissolution rate through liquisolid tablets formulation: In vitro and in vivo evaluation. Eur J Pharm Biopharm 2008;69(3):993-1003.

9. Karmarkar AB, Gonjari ID, Hosmani AH, Dhabale PN, Bhise SD. Dissolution rate enhancement of fenofibrate using liquisolid tablet technique, Part II: Evaluation of in vitro dissolution profile comparison methods. Lat Am J Pharm 2009;28(4):538-43.

10. Singh SK, Srinivasan KK, Gowthamarajan K, Prakash D, Gaikwad NB, Singare DS. Influence of formulation parameters on dissolution rate enhancement of glyburide using liquisolid technique. Drug Dev Ind Pharm 2012;38(8):961-70.

11. Soujanya B, Srujan KM, Subrahmanyam KV, Shubhrajit M. Enhancement of solubility of efaverinz by liquid solid compact technique. Int J Innov Pharm Sci Res 2013;1(3):347-59.

12. Niazi SK. Handbook of Preformulation. USA: Informa Health Care, Inc.; 2007. p. 69, 73, 241, 218, 219, 294, 296, 310-31.

13. Adeyeye MC, Brittain HG. Preformulation in Solid Dosage Form Development. Vol. 178. USA: Informa Health Care, Inc., CRC Press;
2008. p. 369, 559, 562, 565-7.

14. Patel SS, Patel MS, Patel NM. Flowability and packability testing of directly compressible excipients. Indian Pharm 2008;7(71):65-9.

15. Bhise SD, Nand MR. Formulation and evaluation of mouth dissolving tablets of nateglinide. Int J Pharm Pharm Sci 2013;5(4):318-21.

16. Bi Y, Sunada H, Yonezawa Y, Danjo K, Otsuka A, Iida K. Preparation and evaluation of a compressed tablet rapidly disintegrating in the oral cavity. Chem Pharm Bull (Tokyo) 1996;44(1):2121-7.

17. Shoufeng LI, Senshang LI, CheinYie W, Bruce PD, Haresh LM. Statistical optimization of gastric floating system for oral controlled delivery of calcium. AAPS PharmSci Tech 2001;2(1):11-2.

18. Indian Pharmacopoeia. Indian Pharmacopoeia Commission. $6^{\text {th }}$ ed., Vol. I. Ghaziabad: Indian Pharmacopoeia Commission; 2010. p. 587.

19. Bi YX, Sunada H, Yonezawa Y, Danjo K. Evaluation of rapidly disintegrating tablets prepared by a direct compression method. Drug Dev Ind Pharm 1999;25(5):571-81.

20. Khan S, Kataria P, Nakhat P, Yeole P. Taste masking of ondensetron $\mathrm{HCl}$ by polymer carrier system and formulation of rapid disintegrating tablets. AAPS PharmSci Tech 2007;8(2):127-33.

21. Lachman L, Libberman HA, Kanig JL. Theory and Practice of Industrial Pharmacy. $3^{\text {rd }}$ ed. Bombay: Varghese Publishing House; 1990. p. 183, 296-9, 316.

22. Brijesh SD, Avani EA, Madhabai MP. Gastro retentive drug delivery system of ranitidine $\mathrm{HCl}$ : Formulation and in vitro evaluation. AAPS PharmSci Tech 2004;5(2):77-82.

23. Sirisha VN, Sruthi B, Eshwaraiah MC. Preparation and in vitro evaluation of liquid solid compacts of glibenclamide. Int Res J Pharm 2012;3(10):111-4

24. Neelamma G, Chaitanya MV, Satyavathi B. Design and evaluation of solubility enhancement of poorly soluble drug rosuvastatin using liquid solid compacts. Int J Pharmacol Res 2015;5(5):231-8. 